Jurnal Agro Vol. 1, No. 1, Desember 2014

\title{
REKAYASA PUPUK ORGANIK DAN PENGARUHNYA TERHADAP POTENSI HASIL TANAMAN JAGUNG HIBRIDA (Zea mays L.)
}

\section{ORGANIC FERTILIZER ENGINEERING AND EFFECT ON THE YIELD POTENTIAL OF HYBRID CORN (Zea mays L.)}

\author{
Rohana Abdullah \\ Dosen Kopertis Wil 4 Jabar-Banten dpk. Fakultas Pertanian Universitas Bandung Raya \\ Korespondensi : rohana_abd@yahoo.com
}

Diterima 9 Oktober 2014/ Disetujui 12 Desember 2014

\begin{abstract}
ABSTRAK
Penelitian rekayasa pupuk organik dan pengaruhnya terhadap potensi hasil tanaman jagung hibrida (Zea mays L.) telah dilakukan di Kebun Percobaan Fakultas Pertanian Univesitas Padjadjaran sejak Desember 2013 sampai akhir Februari 2014, bertujuan untuk mengetahui pengaruh formula pupuk organik dan dosis terhadap potensi hasil tanaman jagung hibrida. Rancangan percobaan adalah Rancangan Acak kelompok dengan satu faktor perlakuan, yaitu formula pupuk organik A $4 \mathrm{t}$ $\mathrm{ha}^{-1}$ (kompos: jerami $30 \%$, kasmur $10 \%$, limbah buah nenas $20 \%$, kohe sapi $20 \%$, kohe kelinci $20 \%$; 21 kg SP-36+ 4,5 kg KCl 60\% t kompos $^{-1}$ ). B $5 \mathrm{t} \mathrm{ha}^{-1}$ (kompos: jerami 40\%, kasmur 10\%, limbah buah

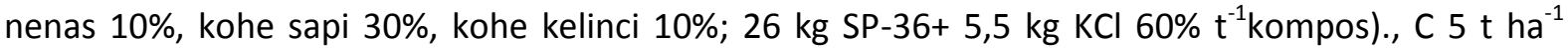
(kompos: jerami 20\%, kasmur 10\%, limbah buah nenas $0 \%$, kohe sapi 50\%, kohe kelinci $20 \%$; $30 \mathrm{~kg}$ SP-36+ $\mathrm{KCl} 60 \%$ 6,0 kg.). , D $4 \mathrm{t} \mathrm{ha}^{-1}$ (kompos: jerami $20 \%$, kasmur $10 \%$, limbah buah nenas $10 \%$, kohe sapi $60 \%$, kohe kelinci $0 \%$; $30 \mathrm{~kg}$ SP-36 +8,5 $\mathrm{kg} \mathrm{t}^{-1} \mathrm{KCl} 60 \%$ ). $5 \mathrm{t} \mathrm{ha}^{-1}$ (kompos: jerami $50 \%$, kasmur $0 \%$, limbah buah nenas 0\%, kohe sapi 50\%, kohe kelinci 0\%; $32 \mathrm{~kg} \mathrm{SP}-36+7 \mathrm{~kg} \mathrm{KCl} \mathrm{60 \%} \mathrm{t} \mathrm{kompos}{ }^{-1}$ ), dan kontrol [K (tanpa formula pupuk organik)]. Hasil penelitian menunjukkan bahwa semua formula pupuk organik berpotensi meningkatkan bobot biomassa kering oven, bobot pipilan kering plot dan potensi hasil tanaman jagung per hektar. Formula $\mathrm{E} 5 \mathrm{t} \mathrm{ha}^{-1}$ berpotensi memberi hasil maksimum 10 t ha ${ }^{-1}$.
\end{abstract}

Kata kunci : Formula Pupuk Organik, Potensi Hasil Jagung

\begin{abstract}
Research about organic fertilizers formulation and its effect on maize yield potency was conducted at experimental field located in Universitas Padjadjaran, Jatinangor Sumedang, West Java, since December 2013 until Februari 2014. The experiment was aimed to determine the effect of organic fertilizers formulas to maize yield potency, which was arranged using a randomized block design and repeated six times with six treatment factors $\mathrm{A} 4 \mathrm{t} \mathrm{th}^{-1}$ (compost of: straw $30 \%$, spent muschroom substrate $10 \%$, pineapple waste $20 \%$, cow dung $20 \%$, rabbit droppings $20 \% ; 21 \mathrm{~kg} \mathrm{SP}-36+4,5 \mathrm{~kg} \mathrm{KCl}$ $60 \% \mathrm{t} \mathrm{compost}^{-1}$ ). B $5 \mathrm{t} \mathrm{ha}^{-1}$ (compost of: straw $40 \%$, spent muschroom substrate $10 \%$, pineapple

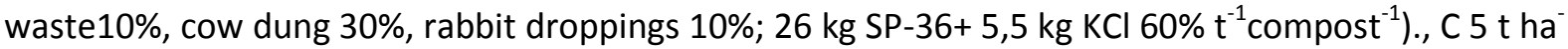
${ }^{1}$ (compost of: straw $20 \%$, spent muschroom substrate $10 \%$, pineapple waste $\%$, cow dung $50 \%$, rabbit droppings $20 \% ; 30 \mathrm{~kg} \mathrm{SP}-36+\mathrm{KCl}_{60 \%} 6,0 \mathrm{kgt}_{\text {compost }}{ }^{-1}$ ), D $4 \mathrm{t} \mathrm{ha}^{-1}$ (compost of: straw 20\%,

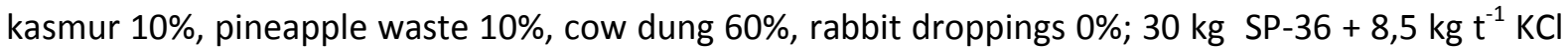


$60 \% \mathrm{t}$ compost $^{-1}$ ). E $5 \mathrm{t} \mathrm{ha}^{-1}$ (compost of: straw $50 \%$, spent muschroom substrate $0 \%$, pineapple waste

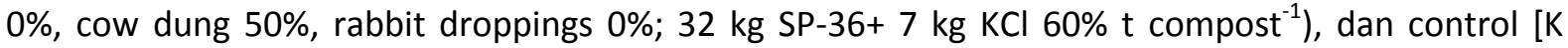
(withouthorganic fertilizer formula)]. The result indicated that organic fertilizer formulas increased dry matter weight, seed dry weight per plot and potential yield per hectare. Organic fertilizer formulas $\mathrm{E} 5 \mathrm{t} \mathrm{ha} a^{-1}$ potentiallygave the maximum yield of $10 \mathrm{t} \mathrm{ha}^{-1}$.

Keys words: Organic Fertilizer Formulas, Maize Yield Potency

\section{PENDAHULUAN}

Pupuk adalah zat yang ditambahkan ke dalam media tanam atau tanaman guna mencukupi kebutuhan hara yang tidak dapat dipenuhi oleh tanah. Secara umum pupuk dapat dibagi ke dalam dua jenis, yaitu pupuk anorganik dan pupuk organik. Pupuk anorganik adalah pupuk hasil rekayasa kimia dengan penambahan jenis dan jumlah unsur hara tertentu. Oleh karena itu terdapat pupuk tunggal yang mengandung satu formula unsur hara dan pupuk majemuk yang mengandung dua atau lebih unsur hara. Pupuk organik adalah hasil dekomposisi sisasisa tanaman, hewan, sampah rumah tangga, sampah pasar, limbah organik industri, dapat memperbaik sifat fisik, kimia dan biologi tanah.

Pupuk anorganik dan pupuk organik sangat penting untuk proses produksi pertanian, oleh karena itu untuk meningkatkan produksi tanaman, kebutuhan kedua jenis pupuk ini terus meningkat. Akan tetapi penggunaannya oleh petani baik pada lahan sawah maupun lahan kering diketahui belum berimbang, umumnya hanya menggunakan pupuk urea sebagai sumber $\mathrm{N}$. Sedangkan pupuk $\mathrm{P}$ dan $\mathrm{K}$ masih rendah penggunaanya dengan dosis yang tidak sesuai anjuran untuk kebutuhan tanah dan tanaman. Pengelolaan hara yang kurang tepat tersebut juga tidak diimbangi oleh penambahan bahan organik yang cukup sehingga terjadi penurunan bahan organik tanah (Irawan et al., 2012).
Pupuk organik dapat dibuat dari berbagai sumber seperti sampah asal rumah tangga, sampah pasar, kotoran hewan dan sisa panen melalui pengomposan (Misra et al., 2003). Beragamnya sumber, formula bahan mentah sumber pupuk organik proses dan metoda yang digunakan dalam pembuatan pupuk organik akan menghasilkan kualitas pupuk organik yang berbeda-beda. Oleh karena itu memerlukan inovasi teknologi untuk pengembangan formula baru sehingga dapat meningkatkan efektifitas dan efesiensi penggunaan pupuk organik pada tanah. Rekayasa pupuk organik dibuat sesuai dengan standar baku mutu pupuk organik yaitu memenuhi kriteria baku mutu pupuk organik telah ditetapkan dalam Peraturan Kementerian Pertanian Republik Indonesia (Kementerian Pertanian Republik Indonesia, 2011).

Hasil rekayasa pupuk organik (formula pupuk organik) diuji efektifitasnya terhadap tanaman jagung di lapangan melalui percobaan. Tanaman jagung banyak diperlukan masyarakat untuk keperluan pangan dan pakan ternak. Penggunaan pupuk organik asal pupuk kandang biasa digunakan oleh petani sebagai penutup benih jagung dengan dosis 3,5 $\mathrm{t} \mathrm{ha}^{-1}$ (Suryana et al., 2009). Karena itu dalam pengujian efektivitas ini dilakukan penggunaan formula pupuk organik A 4 t ha $a^{-1}$, B 5 t ha ${ }^{-1}$, C $5 t_{\text {h ha }}^{-1}$, D 4 t ha ${ }^{-1}$ dan E 5 t ha $^{-1}$ dan Kontrol (K) (Rohana, 2014). Penggunaan pupuk anorganik sesuai anjuran dimaksudkan untuk memenuhi kebutuhan hara tanaman jagung yang mampu 
memberikan hasil berkelanjutan. Tujuan penelitian ini adalah untuk mengetahui pengaruh beberapa formula pupuk organik terhadap bobot biomassa kering oven, hasil dan potensi hasil tanaman jagung hibrida (Zea mays L.).

\section{BAHAN DAN METODE}

Penelitian dilakukan pada tanah Fluventic Hapludults menggunakan tanaman jagung hibrida Bantimurung-3 di kebun percobaan Fakultas Pertanian Universitas Padjadjaran desa Ciparanje, Kecamatan Cikeruh, Sumedang Jawa Barat mulai Desember 2013 sampai akhir Februari 2014. Rancangan percobaan yang digunakan adalah Rancangan Acak Kelompok, dengan faktor jenis pupuk organik dosis tertentu yang terdiri dari 6 taraf, setiap perlakuan diulang 6 kali, sehingga diperoleh 36 unit percobaan. Adapun perlakuan yang dimaksud adalah:Faktor perlakuan jenis pupuk organik diberikan label A-E dan $\mathrm{K}$ untuk kontrol, terdiri dari: Formula $\mathrm{A}_{4}=$ Formula pupuk $\mathrm{A} 4 \mathrm{t} \mathrm{ha}^{-1}$ (80 g tanaman ${ }^{-1}$ ); Formula $B_{5}=$ Formula pupuk B $5 \mathrm{t} \mathrm{ha}^{-1}(100 \mathrm{~g}$ $\operatorname{tanaman}^{-1}$ ); Formula $C_{5}=$ Formula pupuk $C$ dosis $5 \mathrm{t} \mathrm{ha}^{-1}$ (100 g tanaman $\left.{ }^{-1}\right)$; Formula $\mathrm{D}_{4}=$ Formula pupuk $\mathrm{D}$ dosis $4 \mathrm{t} \mathrm{ha}^{-1}(80 \mathrm{~g}$ $\left.\operatorname{tanaman}^{-1}\right)$; Formula $E_{5}=$ Formula pupuk $E$ dosis $5 \mathrm{t} \mathrm{ha}{ }^{-1}$ (100 g tanaman $\left.{ }^{-1}\right)$; dan Kontrol=Tanpa formula pupuk organik.

Formula A (kompos: jerami 30\%, kasmur $10 \%$, limbah buah nenas $20 \%$, kohe sapi $20 \%$, kohe kelinci 20\%; $21 \mathrm{~kg} \mathrm{SP}-36+4,5 \mathrm{~kg} \mathrm{KCl} \mathrm{60 \%}$ t kompos $^{-1}$ ). Formula B (kompos: jerami $40 \%$, kasmur $10 \%$, limbah buah nenas $10 \%$, kohe sapi 30\%, kohe kelinci 10\%; 26 kg SP-36+ 5,5 $\mathrm{kg} \mathrm{KCl} 60 \% \mathrm{t}^{-1}$ kompos). Formula $\mathrm{C}$ (kompos: jerami $20 \%$, kasmur $10 \%$, limbah buah nenas $0 \%$, kohe sapi $50 \%$, kohe kelinci $20 \%$; $30 \mathrm{~kg}$
SP-36+ $\mathrm{KCl} 60 \%$ 6,0 kg.). Formula D (kompos: jerami $20 \%$, kasmur $10 \%$, limbah buah nenas $10 \%$, kohe sapi $60 \%$, kohe kelinci $0 \%$; $30 \mathrm{~kg}$ $\left.\mathrm{SP}-36+8,5 \mathrm{~kg} \mathrm{t}^{-1} \mathrm{KCl} 60 \%\right)$. Formula E (kompos: jerami 50\%, kasmur 0\%, limbah buah nenas $0 \%$, kohe sapi $50 \%$, kohe kelinci 0\%; $32 \mathrm{~kg} \mathrm{SP}-36+7 \mathrm{~kg} \mathrm{KCl} 60 \%$ t kompos $^{-1}$ ). $\mathrm{K}$ (tanpa formula pupuk organik). Variabel yang diamati adalah bobot biji kering per plot.Data pengamatan dianalisis dengan Anova, apabila terdapat keragaman dilanjutkan dengan uji Duncan pada taraf $5 \%$.

\section{HASIL DAN PEMBAHASAN}

\section{Bobot Biomasa Kering Oven}

Berdasarkan analisis ragam pengaruh formula dan dosis pupuk organik berpengaruh nyata terhadap biomassa kering. Semua formula dan dosis pupuk organik dapat meningkatkan bobot biomassa kering, akan tetapi sesama formulasi pupuk organik memberikan hasil yang sama dan berbeda. Formulasi E $5 \mathrm{t} \mathrm{ha}^{-1}$ memberi nilai bobot biomassa kering lebih tinggi dari formula $\mathrm{C} 5 \mathrm{t}$ ha ${ }^{-1}$.

Formula pupuk organik E yang terdiri dari bahan kompos jerami padi dan kotoran hewan (kohe) sapi diduga mengandung senyawa $\mathrm{SiO}_{2}$ lebih tinggi. Jerami padi mengandung SiO (Simarmata dan Joy, 2011) sekitar 3\%-5\% yang disusul oleh unsur Nitrogen dan Kalium, menyebabkan daun tanaman tumbuh tegak sehingga lebih efesien dalam penyerapan sinar matahari (Havlinet al., 2004). Silikat bukan merupakan unsur hara esensial pada tanaman, akan tetapi pada beberapa tanaman terutama tanaman gramine mempunyai arti penting dalam pertumbuhan tanaman (Syafruddin, 2011). 
Tabel 1. Bobot Biomasa Kering dengan Perlakuan Formula, dan Dosis Pupuk Organik

\begin{tabular}{|c|c|c|}
\hline \multirow[t]{2}{*}{ Perlakuan } & \multicolumn{2}{|c|}{ Bobot biomasa kering } \\
\hline & $--g--$ & \\
\hline Formula A $4 \mathrm{t}$ & 138,0 & $a b$ \\
\hline Formula B 5 t & 143,4 & $a b$ \\
\hline Formula C $5 \mathrm{t}$ & 132,9 & $b$ \\
\hline Formula D 4 t & 134,2 & $a b$ \\
\hline Formula E 5 t & 147,9 & a \\
\hline Kontrol & 100,4 & c \\
\hline \multicolumn{3}{|c|}{ 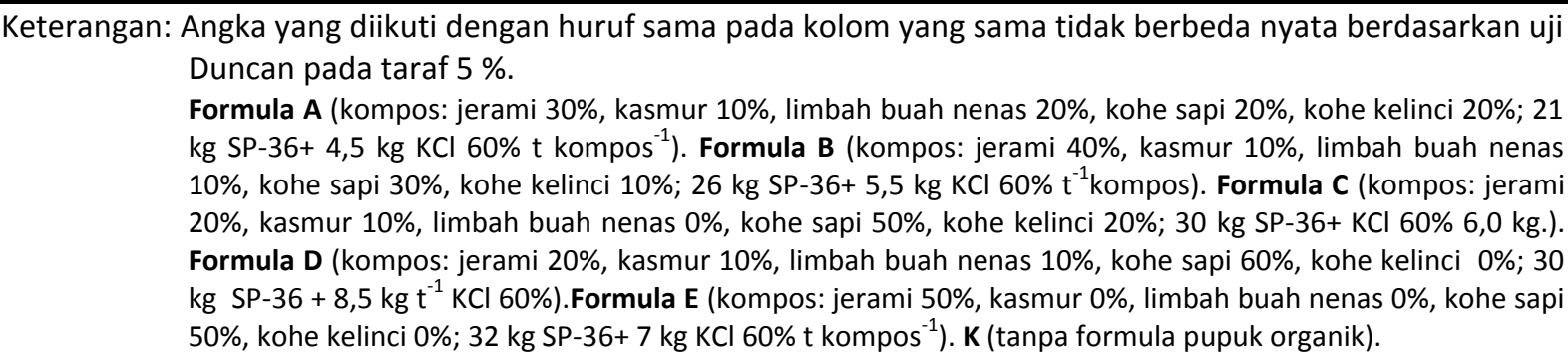 } \\
\hline
\end{tabular}

\section{Bobot Biji per Plot dan Potensi Hasil Jagung}

Berdasarkan analisis ragam pengaruh formula dan dosis pupuk organik berpengaruh bobot biji pipilan kering per plot. Berdasarkan Tabel 2 menunjukkan bahwa semua jenis formula pupuk organik dapat meningkatkan hasil lebih $26,4 \%$ pada bobot biji perplot dan
25,9\% pada potensi hasil, dengan potensi hasil maksimum $10,0 \mathrm{t} \mathrm{ha}{ }^{-1}$, sesuai dengan potensi hasil tanaman jagung hibrida Bantimurung-3. Hal ini dapat dihubungkan dengan bobot biomassa kering oven bahwa pertumbuhan vegetatif baik dapat mendukung produktivitas hasil jagung yang tinggi.

Tabel 2.Bobot Hasil Biji Per Plot dan Potensi Hasil dengan Formula, dan Dosis Pupuk Organik

\begin{tabular}{ccc}
\hline Perlakuan & $\begin{array}{c}\text { Bobot hasil biji petak } \\
\left(\mathrm{kg}^{-1} 6 \mathrm{~m}^{-2}\right)\end{array}$ & $\begin{array}{c}\text { Potensi hasil } \\
(\mathrm{t} \mathrm{ha}\end{array}$ \\
\hline Formula A 4 t & $5,32 \mathrm{a}$ & 8,9 \\
Formula B 5 t & $5,32 \mathrm{a}$ & 8,9 \\
Formula C 5 t & $5,39 \mathrm{a}$ & 9,0 \\
Formula D 4 t & $5,88 \mathrm{a}$ & 9,8 \\
Formula E 5 t & $6,02 \mathrm{a}$ & 10,0 \\
K & $4,42 \mathrm{~b}$ & 7,4 \\
\hline CV (\%) & 12,36 & \\
\hline
\end{tabular}

Keterangan:Angka yang diikuti dengan huruf samapada kolom yang sama tidak berbeda nyata berdasarkan uji Duncan pada taraf $5 \%$.

Formula A (kompos: jerami 30\%, kasmur 10\%, limbah buah nenas 20\%, kohe sapi 20\%, kohe kelinci 20\%; 21 $\mathrm{kg} \mathrm{SP}-36+4,5 \mathrm{~kg} \mathrm{KCl} 60 \% \mathrm{t} \mathrm{kompos}^{-1}$ ). Formula B (kompos: jerami $40 \%$, kasmur 10\%, limbah buah nenas $10 \%$, kohe sapi 30\%, kohe kelinci 10\%; $26 \mathrm{~kg} \mathrm{SP}-36+5,5 \mathrm{~kg} \mathrm{KCl} \mathrm{60 \%} \mathrm{t}^{-1}$ kompos). Formula C (kompos: jerami

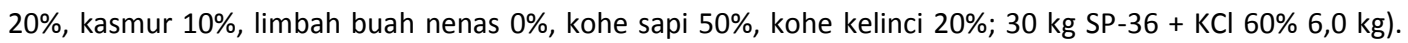
Formula D (kompos: jerami 20\%, kasmur 10\%, limbah buah nenas 10\%, kohe sapi 60\%, kohe kelinci $0 \%$; 30 kg $\mathrm{SP}-36+8,5 \mathrm{~kg} \mathrm{t}^{-1} \mathrm{KCl} 60 \%$ ). Formula $\mathbf{E}$ (kompos: jerami 50\%, kasmur $0 \%$, limbah buah nenas $0 \%$, kohe sapi $50 \%$, kohe kelinci 0\%; $32 \mathrm{~kg} \mathrm{SP}-36+7 \mathrm{~kg} \mathrm{KCl} \mathrm{60 \%}$ k kompos $^{-1}$ ). $\mathbf{K}$ (tanpa pupuk organik).

Bahan organik merupakan sumber unsur hara $\mathrm{N}, \mathrm{P}$, dan $\mathrm{S}$ untuk tanaman. Ketersediaan fosfat tanah meningkat dengan penambahan bahan organik, karena terjadi khelat pada 
pada unsur hara mikro seperti Fe (Stevenson, 1994). Formula pupuk organik sesuai standar Permentan bersama pupuk anorganik sesuai anjuran yang diikuti oleh air tersedia cukup, dapat menyediakan unsur hara yang sesuai untuk petumbuhan dan hasil tanaman jagung.

\section{SIMPULAN DAN SARAN}

\section{Simpulan}

1. Formula pupuk organik mempengaruhi bobot biomasa kering oven dan bobot biji pipilan kering.

2. Semua formulasi pupuk organik berpotensi meningkatkan bobot biomasa kering oven dan hasil jagung per hektar, khusus Formula $\mathrm{E}$ dosis 5 ton $\mathrm{ha}^{-1}$ memberikan hasil sesuai diskripsi tanaman jagung Bantimurung-3.

\section{Saran}

1. Semua formula dan dosis pupuk dapat dianjurkan penggunaanya dalam batasbatas kesamaan faktor tanah dan lingkungan.

2. Untuk mengetahui kekuatan, kelamahan, peluang dan ancaman pada masingmasing formula dan dosis pupuk organik diperlukan uji dan verifikasi hasil percobaan demplot pada kondisi lingkungan dan musim berbeda.

3. Penggunaan pupuk organik sangat dianjurkan bersama dengan penggunaan pupuk anorganik untuk memperbaiki kesuburan fisik, kimia dan biologi tanah sehingga berpotensi meningkatkan hasil tanaman jagung.

\section{DAFTAR PUSTAKA}

Havlin, J.L., Tisdale. S.L., Nelson, W.L., dan Beaton, J.D. 2004. Soil Fertility and Fertilizers: An Introduction to Nutrient
Management (7th Edition). (p. 528). Prentice Hall.

Irawan, IGM. dan Subiksa E. H. 2012. Verifikasi Inovasi Teknologi Pupuk dan Bahan Organik melalui Demplot Pemupukan Berimbang pada Lahan Sawah dan Lahan Kering. Balai Penelitian Tanah Bogor.

Kementerian Pertanian Republik Indonesia. 2011. Peraturan Menteri Pertanian Nomor: 70/Permentan/SR.140/10/2011 Tentang Pupuk Organik, Pupuk Hayati, dan Pembenah Tanah.

Misra, R.V dan R.N Roy, H. H. 2003. On-Farm Composting Methods (2nd ed.). Roma: Food and Agriculture organisation of united nation.

Rohana Abdullah. 2014. Beberapa Sifat Tanah Fluventic Dystrudepts dan Produktivitas Tanaman Jagung (Zea mays L.) akibat Pemberian Formula dan Dosis Pupuk Organik (tidak dipublikasi). Universitas Padjadjaran.

Simarmata, T. dan Joy, B. 2011. Pemulihan Kesehatan dan Peningkatan Produksi Padi pada Lahan Suboptimal dengan Teknologi Intensifikasi Padi Aerob Terkendali Berbasis Organik IPAT-BO. Pupuk dan Nutrisi Organik ABG.http://pupukabg.com/Teknologi_Pemulih_lahan_saw ah.php.

Stevenson, F. J. 1994. Humus Chemsetry: Genesis, composition, Reaction (2nd ed., p. 248). Canada: John Willey and Sons.

Suryana, A., Suyamto, Zubachtirodin, Pabbage, M. S., dan Saenong, S. 2009. Buku Panduan Teknis PTT Jagung. In Litbang Deptan (Ed.), Jagung Teknik Produksi dan Pengembangan (p. 27). Pasar Minggu Jakarta Selatan: Badan Penelitian dan Pengambangan Pertanian. 
Syafruddin. 2011. Pengaruh Silikat terhadap Hasil dan Efisiensi Pemupukan P pada

Tanaman Jagung. Seminar Nasional Serealia, 280-286. Retrieved from http://balitsereal.litbang.deptan.go.id/in d/images/stories/24bpros11.pdf. 